\title{
BIM BASED PROJECT AND DIGITAL BUILDING MODEL MANAGEMENT: APPLICATIONS AND EMERGING STANDARDS
}

\author{
DOI: 10.18485/arh_pt.2020.7.ch46
}

\section{_ Igor Svetel}

Innovation Center, Faculty of Mechanical Engineering, University of Belgrade, Kraljice Marije 16, 11000 Belgrade, isvetel@mas.bg.ac.rs

\author{
- Nenad Ivanišević \\ Faculty of Civil Engineering, University Of Belgrade, \\ Bulevar kralja Aleksandra 73, nesa@grf.bg.ac.rs

\section{_ Dušan Isailović \\ Faculty of Civil Engineering, University Of Belgrade, Bulevar kralja Aleksandra 73, disailovic@grf.bg.ac.rs}

\begin{abstract}
Architectural design and building construction are increasingly digitalized. A large number of applications exist that enable creation of digital building models either in the form of advanced geometry modelling applications, algorithmic modelling applications or BIM applications. Each application creates intrinsic digital model using its proprietary data format. The problem of connecting such diverse models to a coherent project environment is addressed by open interoperability file format IFC. But only data format does not provide seamless interoperability, it is necessary to create proper IFC model for each particular occasion of model exchange.

Existence of many diverse files and formats that all represent different aspects of digital building model posed to the AEC stakeholders the problem of managing a BIM project. The paper gives a historical overview of development of BIM applications dedicated to digital building model assessment from model viewers, through model explorers, to modern BIM project management applications and their connection to a set of ISO 19650 standards. The new standards and related applications does not provide complete solution to the management of digital building models but represent important evolutionary step in BIM progress.
\end{abstract}

KEYWORDS _ digital building model, BIM, model lifecycle management, BCF, ISO 19650

\section{INTRODUCTION}

Building Information Modelling (BIM) evolved as a blend of different CAD (Computer Aided Design) technologies. Among the first commercial applications was ARCHICAD, a program that made it possible to produce consistent traditional project documents (plans, sections, layouts etc.) from a basic $3 \mathrm{D}$ building model. The problem of time consuming creation of a 3D model based on the definition of the coordinates of the points and the description of the surfaces that close the 3D body has been solved by introducing parametric objects that define the basic components of a building such as slabs, walls, windows, stairs, etc. (Svetel, Kosić 2017). In addition to geometry information, these objects also had information about classes, relationships, and features, such as material type, role in a building, etc. In this way, when modelling, objects automatically performed certain operations, 
such as creating openings in the wall when installing a window or joining the same materials when intersecting walls.

Soon a new application with similar functionality appeared. Revit provided creation of building models based on parametric objects that mimic building components and automatic combination of elements based on their functions. The new functionality was support for model revisions. Unlike ARCHICAD, Revit had a far more complex structure of relations between elements that allowed model parameters to be updated automatically depending on changes in the values of the parameters with which they were associated.

At about the same time, the International Alliance for Interoperability (IAI) was formed with a goal to develop an object oriented data model to attain highest level of interoperability in architecture and construction software applications (Svetel 2007). The result was Industry Foundation Classes (IFC) a neutral and open model that became the international standard for interoperability among BIM applications, and IAI transformed into buildingSMART, a leading authority in the exchange of information among software applications in Architectural, Engineering and Construction (AEC) field. The first version that was candidate for the international standard appeared in 2005 as the ISO/PAS 16739:2005 (ISO 2005).

As the technologies described above began to be implemented in AEC firms, other software developers who had advanced 3D modelling applications improved their systems to deal with parametric objects that represent building components so more applications resembling ARCHICAD and Revit functionality appeared on the market. Soon a term Building Information Modelling (BIM) appeared to describe this technological advancement. However, instead of describing only existing technologies, the term was also used to depict all possible advancements in the AEC field (Succar 2009) that lead to further advancement in the field, but also created some exaggerated expectations and disappointments because existing applications do not achieve this functionality, known today as "BIM utopia" (Miettinen and Paavola 2014). In these pioneering days everyone was trying to get the best support for the new international standard IFC, so they used every opportunity to do so, often causing the model to be fully exported and imported within the application itself, while bugs occurred with applications from other software vendors. Since, without a detailed knowledge of the structure of the IFC file, it was not possible to determine whether an error in the transfer of information occurs in the export of one or the import of another application, IFC viewers appeared very quickly as applications that enabled independent analysis of IFC models. The first was Nemetschek IFC Viewer (AllPlan 2007) and soon DDS-CAD Viewer, Solibri Model Viewer and Tekla BIMsight followed.

\section{MODEL VIEWERS}

Although they did not attract much attention at the time of the appearance, the model viewers did represent a significant improvement in BIM technology. At the time, BIM applications were viewed only as tools for creating architectural documentation using a computer and IFC file as a data exchange format. Model viewers for the first time turned designers' attention to the digital building model that underlies all BIM technology. Through these applications, users could clearly see that the IFC file contained a complete model of the building that is designed.

The basic functionality of these applications that caught the attention of most users is the ability to visually analyze the model without having to own commercial BIM applications. IFC model viewers allow the user to see 3D representation of the model, and model tree representing hierarchy of objects in the IFC format. Majority of viewers enables switching on/off visibility or changing transparency of particular objects or classes in the tree providing better visual understanding of the model. Some applications enable insertion of clipping planes in the model providing 3D sections and plans in the model. All application enables viewing the building through the rotation around the model or by creating a walk through the model. Some applications simulate walking through the model to the level of hitting objects, gravity impact (walk on stairs) and falling from a height. The model tree enables the user to comprehend whole structure and hierarchy of classes and objects in the IFC for- 
mat. By selecting any point in the tree, a user can see all properties related to that particular class or object. This functionality was very important in the pioneering days since it enabled users to resolve problems in the interoperability among BIM applications at to detect sources of errors.

Most model viewers evolved during a time into model explorers, but some applications retained only basic functionality. Most notable is free Graphisoft BIMx that enables integration of 3D model with $2 \mathrm{D}$ documentation and enables viewing complex ARCHICAD models on desktop computers or mobile devices.

\section{MODEL EXPLORERS}

The possibilities of further analysis of the 3D models were quickly realized. Among first introduced functions was ability to record viewpoints, make comments and share them with other participants in design process. Soon, ability to take measurements and make marks on the 3D model was introduced. Next introduced functionality was clash detection.

In contrast to model viewers that enable users to load only one model, most modern model explorers support loading of multiple models and creation of so-called federated model. Federated models can be created from a single file type, mostly IFC, or from different file types. Some applications merge the loaded models into one unique model, while others keep loaded models separate, but let the user to view and perform all operations (such as clash detection) on a whole federated model. The model storage can be local, but most applications support cloud based storage systems that make models available to all participants all the time and at all places. Most applications allow enrichment of the model content by insertion of various other formats that describe the model, e.g. 2D drawings, catalogues, photos, text reports, etc. In recent years, a large number of applications that support this functionality have emerged on the market. As this area is subject to change and improvement over time, most applications allow users to develop the improvements they need on their own using the open application-programming interface (API).

BIM 360 (Autodesk 2020a) is a set of cloud-based services that supports mainly Autodesk BIM formats. It enables loading of the Revit models, and creates federated model. The model can be explored as the whole or selected parts based on levels or teams can be accessed. It also enables view of attached files to the Revit model, like 2D plans. Different cloud services support document management, clash detection, issue management, collaboration, and project management. The system provides specific cooperation management environment based on teams and packages. Visual timeline has separate line for each team that shows when particular set of data (package) is uploaded to cloud. New package can be analyzed by all project members and then "consumed" meaning that the package is combined with another team's model. Automated change visualization shows added, removed and modified packages.

Trimble Connect (Trimble 2020) is the cloud service with desktop, web and mobile clients. It loads IFC and other models and allows operations on a federated model while keeping files separate organized in folders. The system is collaboration platform that organizes stakeholders into teams and allows them to share information like models, drawings and documents by creating release packages that are then available to all stakeholders for revision. The application supports issue management, clash detection and team management. The application also provides open API that enables better integration with other applications.

3D Repo (3D Repo 2020) is the web based cloud service that creates federated model by combining uploaded models in IFC, RVT, DGN, BCF, FBX and OBJ formats. Separate Navisworks Plugin enables upload of other Autodesk formats. The application allows user to add over 40 different formats to the model as documentation for issue management. It supports smart groups as the way for data validation; change detection, clash detection and issue management that takes into account groups from which data originated and enables all stakeholders to monitor data and its progress. The application also contains health and safety information that can be associated with the model for project risks management. The system's functionality can be enhanced width add-ons made using server 
and viewer $\mathrm{API}$.

BIMcollab ZOOM (BIMcollab 2019) is the free application that enables creation of federated model from multiple IFC files. The application shows each model separately as the part of the federated model. New IFC models can be added to federated model at any time. The commercial application enables users to perform issue detection, clash detection, data extraction (quantity and property) and validation of any object, classification or property against requirements.

SimpleBIM (SimpleBIM 2020) is different kind of BIM explorer. It is desktop application that enables creation of federated IFC models, but contrary to other described applications, it enables optimization and enrichment of IFC models. The application enables trimming, cleaning, splitting or merging model in order to fit requirements. The user can include or exclude model elements, edit values, associate elements with missing information or with appropriate classes, edit the correct model structure, and edit locations. There is an option to automate the described processes through the application of templates. The program also offers tools that automatically or through user interaction solve problems most commonly encountered with IFC models and their combination into federated models. Particularly interesting is the Appearance Editor, which allows user to assign arbitrary colour combinations to the elements of an IFC model. This process can be automated using Excel spreadsheets, allowing the results of different simulations to be linked to model elements by associating simulation values with specific element colours. This overcomes the usual one-way flow of information from BIM models to building energy simulation programs (Svetel et al. 2018) and provides feedback from simulations to BIM models. The open API enables users to customize system to their needs.

\section{BIM BASED PROJECT MANAGEMENT}

Navisworks (Autodesk 2020b) is most notable for its support for a wide range of design file formats like IFC, DWG, DXF, 3DS, SKP. It creates federated proprietary model that integrates multiple files by saving references to original project files. The application enables navigation through model and creation of various model presentations. It supports clash detection, issue management, creation of 4D construction sequencing (Time Liner) by linking Gant charts from project management software. Using Quantification functionality users can automatically make material estimates, measure areas and count building components.

Bexel Manager (Bexel 2020) is the application that was developed specifically to support AEC project management, based on the experience with large real life projects. The application creates locally stored federated model with proprietary data structure from separate IFC models. From the latest version (10.21.2), the application supports IFC export enabling Bexel Manager to integrate in BIM workflow. The application supports traditional model exploring based on IFC model structure and adds ability to group elements in custom defined selections sets and to make custom breakdowns of the model. It enables in-model measurement and clash detection. The main functionality is directed toward assigning cost and time information to model elements and automated creation of cost estimations, schedules and construction simulations. It enables users to link documents to model and use BCF Manager for collaboration. The application provides users with open API either as in-application API window or by inclusion of compiled add-ins to application. Add-ins enable users to adapt applications to their needs and provide means to integrate Bexel Manager in BIM workflow.

\section{COOPERATION MANAGEMENT}

With the development of applications that enabled exploration and issue detection in BIM models, the need arose to share this information among project participants. Some software companies tried to develop custom protocols, but soon it was clear that common solution is needed. The BIM Collab- 
oration Format (BCF) was developed by Tekla and Solibri and later accepted by buildingSMART and published as the standard for the issue management collaboration in BIM (buildingSMART 2020). Before the standard, it was necessary to transfer whole BIM model between stakeholders to account for issues detected in the model. The BCF is the XML schema that records only detected issues, requests or proposals and connects them to the BIM model. First, it was only file based format, but with the development of bcfAPI it is now implemented as server based service. The Vectorworks, ArchiCAD, Revit, Tekla Structures, DDS CAD, Bexel Manager, Solibri, TrimbleConnect, Navisworks, simpleBIM support BCF format and many more BIM applications are incorporating this format into their workflows. The format enables users to create, sort out and explore issues directly in their BIM model. Some aspects of the process are structured but naming of the issue, descriptions and comments are conducted in ordinary language that needs agreement among stakeholders.

The BCF standard does not solve all cooperation problems. Software developers add additional layers of cooperation management to their systems. Permission management enables control of who can access, modify or decide about status of particular files. Team management defines which profession access specified part of the system. Time line indicates when particular model is uploaded to the system for others to see.

\section{PROJECT MANAGEMENT AND MODEL LIFECYCLE MANAGEMENT}

Increased understanding of the role of the digital building model in BIM workflow and the development of applications that support it has led to the need to systematize the whole process. The result is a set of ISO 19650 standards grouped under the name 'Organization and digitization of information about buildings and civil engineering works, including building information modelling (BIM) - Information management using building information modelling' that lay the foundations for moving from file based BIM to model based BIM. The standards are applicable to all built assets and construction projects regardless of their size or complexity. At the moment two parts of the standard are published, part 1 that sets concepts and principles, and part 2 that sets specific requirements for information management during delivery phase

The standard ISO 19650 - Part 1 (ISO 2018a) defines the AEC process using BIM technology as the transition of digital building model from project information model to asset information model, where former contains necessary information to carry on and complete building construction and later all necessary information for maintaining built asset. The management of the whole process is put into the hands of project managers who traditionally managed the process of building the facility.

In order for the process to take place, it is necessary to determine common data environment implemented as the federated information model. It is a source of information (set of structured and unstructured information containers) on which all stakeholders agree and that represents a "source of truth" for their decision-making. Information container is any set of information retrievable from file, system or storage hierarchy. The collection, management and dissemination of information should be carried out through a managed collaborative process. The process should recognise different information management perspectives and to proceed in accordance with information requirements. Project and asset information are specified progressively throughout the information life cycle and are drawn from the whole delivery team through a check/review/approve transition. Every participant in the process should adhere to the information handover principles and initiate horizontal collaboration within a single project phase or set of participants as well as vertical reuse of data for participants further along the project pipeline. To keep the process running efficiently the standard identifies the types of information management functions and their responsibilities.

The ISO 19650 - Part 2 (ISO 2018b) explains processes of information management in the delivery phase which goes through phases of appointment of information management function, through establishing project information requirements, information delivery milestones, information standards, information production methods, shared resources, common data environment, and information protocol. 
One of important activities is definition of BIM Execution Plan (BEP) that goes through phases of establishing pre-appointment plan, through assessing teams' capability and capacity, mobilization plan, and risk register, to the confirmation of the delivery team's BIM execution plan and responsibility matrix.

The information that is created during collaborative production of information should fulfil all defined information needs but not exceeds or extends beyond the information need. The authorization of information should be conducted by lead appointed party before the project is closed and archived.

\section{CONCLUSIONS}

While in the literature BIM is treated as the model-based approach, many practitioners treat the digital model only as a data-containing structure. The difference between data structures and models is that the former contain only slots for fast retrieval of information, while the latter contain relations, processes and other contents that allow simulations to be made over the model and new conclusions drawn from this (Svetel et al. 2018). For now, people using BIM are carriers of knowledge about relationships and processes, and they use BIM data structures to draw conclusions. In practice, BIM has not yet reached the level of the model that by its existence brings new values to the AEC process itself.

The new standards still do not give sufficient importance to the digital building models. They treat them under the term Information Container and Common Data Environment, which enables many different data structures to be used in the process. The digital model is still regarded as an external thing in the AEC process that serves to transmit information, not as the core around which the whole process is organized and that evolves from conceptual design to a construction design and to a model of a built facility in the end.

On the other hand, these standards and related applications represent important evolutionary step in BIM progress. The first BIM applications were evaluated based on the quality of the drawings they produced. With the detection of IFC format issues, attention has turned to the quality of the digital model. With the advent of the ISO 19650 standard, attention is focused on the quality of federated models and the ability to establish efficient cooperation based on the digital model. Contrary to the time when BIM applications and IFC standard where seen as sufficient to make revolution in AEC field, these standards take into account the real current needs of the industry and take a step forward based on existing technological solutions. Just as problems with the implementation of IFC standards have led to the emergence of new applications and technologies that eventually enabled the practical implementation of the principles of the new standards, we can expect that probable problems with the implementation of the new standards will lead to the further development of BIM technologies.

\section{ACKNOWLEDGMENTS}

This research was supported by the Ministry of Education, Science and Technological Development of the Republic of Serbia under grant TR-36038.

\section{REFERENCES}

_ 3D Repo. 2020. "The Digital Platform for BIM Data." Accessed March 15, 2020. https://3drepo.com/.

_ AllPlan. 2007. "Nemetschek presents first universal tool for IFC." Last modified May 02 2007. Accessed 
March 15, 2020. https://www.allplan.com/en/press-reports/press-report/nemetschek-presents-firstuniversal-tool-for-ifc.

_ Autodesk. 2020a. "BIM 360." Accessed March, 2020. https://www.autodesk.com/bim-360/.

_ Autodesk. 2020b. "Nawisworks." Accessed March, 2020. https://www.autodesk.com/products/ navisworks/overview.

_ BIMcollab. 2019. "BIMcollab ZOOM." Accessed March 15, 2020. https://www.bimcollab.com/en/ Products/zoom.

_ Bexel. 2020. "Bexel Manager." Accessed March 15, 2020. https://bexelmanager.com/.

_ buildingSMART. 2020. "BIM Collaboration Format (BCF)." Accessed March 15, 2020. https://technical. buildingsmart.org/standards/bcf/.

_ EFCA. 2019. BIM and ISO 19650 from a project management perspective. Brussels: EFCA https://www. efcanet.org/sites/default/files/2020-01/390764_BIM\%20booklet.pdf.

_ ISO. 2005. "ISO/PAS 16739:2005 Industry Foundation Classes, Release 2x, Platform Specification (IFC2x Platform)." Last modified October 2005. Accessed March 15, 2020. https://www.iso.org/standard/38056.html.

_ ISO. 2018a. "ISO 19650-1:2018 Organization and digitization of information about buildings and civil engineering works, including building information modelling (BIM) - Information management using building information modelling - Part 1: Concepts and principles." Last modified December 2018. Accessed March 15, 2020. https://www.iso.org/standard/68078.html.

_ ISO. 2018b. "ISO 19650-2:2018 Organization and digitization of information about buildings and civil engineering works, including building information modelling (BIM) - Information management using building information modelling - Part 2: Delivery phase of the assets." Last modified December 2018. Accessed March 15, 2020. https://www.iso.org/standard/68080.html.

_ Miettinen, Reijo and Paavola, Sami. 2014. "Beyond the BIM utopia: Approaches to the development and implementation of building information modeling." Automation in Construction 43, (July): 84-91.

_ SimpleBIM. 2020. "SimpleBIM: Makes BIM Normal." Accessed March 15, 2020. https://simplebim. com/.

_ Succar, Bilal. 2009. "Building information modeling framework: A research and delivery foundation for industry stakeholders." Automation in Construction 18, no. 3 (May): 357-75.

_ Svetel, Igor. et al. 2017. "Expectations, Reality and Perspectives in Using BIM for the Green Building Design." Structural Integrity and Life 17, no. 3 (December): 229-34.

_ Svetel, Igor, and Tatjana Kosić. 2017. "Digital and Architecture: Still Not a Perfect Match." In ON ARCHITECTURE Conference Proceedings, 175-182. Belgrade: Strand.

_ Svetel, Igor, et al. 2018. "Digital vs. Traditional Design Process." In Proceedings of 5th International Academic Conference on Places and Technologies, "Places and Technologies 2018 - Keeping up with technologies to adapt cities for future challenges", 453-460. Belgrade: Faculty of Architecture, University of Belgrade.

_ Trimble. 2020. "Trimble Connect." Accessed March, 2020. https://connect.trimble.com/. 